\title{
Placental Growth Factor Promotes Ovarian Cancer Cell Invasion via ZEB2
}

\author{
Ning Song Hao Liu Xiaoxin Ma Shulan Zhang \\ Department of Obstetrics and Gynecology, Shengjing Hospital of China Medical University, Shenyang, \\ China
}

\section{Key Words}

Ovarian cancer (OVC) • ZEB2 • MAPK-p38 signaling pathway • Cancer invasion

\begin{abstract}
Background/Aims: The aggressive manner of ovarian cancer (OVC) cells accounts for the majority of its lethality. Recently, we have shown that placental growth factor (PLGF) promotes metastases of OVC cells through miR-543-regulated MMP7. In the current study, we analyzed the effects of PLGF on another cell invasion associated protein, ZEB2, in OVC cells. Methods: The PLGF and ZEB2 levels in OVC tissues were compared to the paired adjacent non-tumor ovary tissue. We modified ZEB2 levels in OVC cells, and examined its effects on PLGF mRNA and protein levels by RT-qPCR and by Western blot, respectively. We also modified PLGF levels in OVC cells, and examined its effects on ZEB2 mRNA and protein levels by RT-qPCR and by Western blot, respectively. Then, we examined the cell invasiveness in PLGF-modified OVC cells in a transwell cell invasion assay. Finally, we used specific signal pathway inhibitors to treat PLGF-modified OVC cells and examined the effects on ZEB2 activation. Results: PLGF and ZEB2 levels were both significantly increased in OVC tissues, compared to the paired adjacent non-tumor ovary tissue. The PLGF and ZEB2 levels were strongly correlated. ZEB2 modification did not alter PLGF levels. Overexpression of PLGF in OVC cells significantly increased ZEB2 levels and cell invasiveness, while PLGF depletion in OVC cells significantly decreased ZEB2 levels and cell invasiveness. Application of a specific MAPK-p38 inhibitor, but not application of specific inhibitors for MAPK-p42/p44, PI3k/Akt, or JNK signaling pathways, to PLGF-overexpressing OVC cells substantially abolished the PLGF-induced ZEB2 activation. Conclusion: PLGF enhances OVC cell invasion through MAPK-p38-dependent activation of ZEB2.
\end{abstract}

(C) 2016 The Author(s)

Published by S. Karger AG, Basel

\section{Introduction}

Ovarian cancer (OVC) accounts for a minor percentage in all cancers among women. However, OVC is often more malignant than other cancers of the female reproductive system, resulting in a poor prognosis due to the highly aggressive nature of OVC cells $[1,2]$. Hence, elucidation of the molecular mechanisms underlying OC cell invasion is very critical for efficient therapy [3-7]. 


\section{Cellular Physiology Cell Physiol Biochem 2016;38:351-358 \begin{tabular}{l|l|l} 
DOI: 10.1159/000438635 2016,2016 & $\begin{array}{l}\text { C) 2016 The Author(s). Published by S. Karger AG, Basel } \\
\text { www.karger.com/cpb }\end{array}$
\end{tabular} \\ Song et al.: PLGF Promotes OVC Cell Invasion via ZEB2}

Cancer-related angiogenesis plays an essential role in cancer invasion and metastasis, in which it provides tumor with oxygen and nutrients as well as a metastasis channel. Cancer cells often secrete proteinases to break through protein barriers in the extracellular matrix [8]. Vascular endothelial growth factor (VEGF) family is the most important signal protein in vasculogenesis and angiogenesis [9]. The VEGF family is composed of six secreted proteins: VEGF-a, VEGF-b, VEGF-c, VEGF-d, VEGF-e and placental growth factor (PLGF) [10, 11]. PLGF may play an important role in the pathological angiogenesis, in a coordinated way with other VEGF family members. However, the exact effect of PLGF on cancer neovascularization may be case-dependent. For example, PLGF produced by tumor and host cells has been reported to promote angiogenesis and tumor growth [12], or inhibit tumor angiogenesis by forming inactive VEGF/PLGF heterodimer [13].

Epithelial-Mesenchymal Transition (EMT) is a critical biological event involving modification of the cancer cell phenotype to favor its invasiveness and metastases [7, 1418]. MMP7 is an important matrix proteinase from MMP family. Recently, we showed that PLGF promotes metastases of OVC cells through miR-543-regulated MMP7.

The transcription factor ZEB1 and ZEB2 are two important EMT-associated proteins [19]. ZEB1 and ZEB2 are critical for maintenance of an adapted mesenchymal cell phenotype, as well as for EMT induction [20]. Previous approaches have found that ZEB proteins possess zinc-finger clusters in all their $\mathrm{N}$-terminal, central and $\mathrm{C}$-terminal regions to selectively bind to an E-box sequence CACCTG on the DNA of target genes, e.g. E-cadherin [20]. Loss of E-cadherin as well as activation of Vimentin is not only the trigger and dependent process, but also the manifestation for adaption of an epithelial cell to a mesenchymal phenotype. In the current study, we analyzed the effects of PLGF on ZEB2 in OVC cells, which has not been studied before.

\section{Materials and Methods}

\section{Patient specimens}

Resected OVC specimens were collected from 25 OC patients (age: 27 to 54, median 43) in this study. OVC specimens were compared with the paired adjacent non-tumor ovarian tissue (NT) from the same patient. All specimens were histologically and clinically diagnosed at Shengjing Hospital of China Medical University from 2009 to 2014. OVC vs NT was determined based on pathological and/or cytological evidence. The histological features of the specimens were evaluated by senior pathologists according to the World Health Organization classification criteria. Tissues were obtained prior to chemotherapy and radiotherapy and were immediately frozen and stored at $-70^{\circ} \mathrm{C}$ prior to Western blot. For the use of these clinical materials for research purposes, prior patient's consents and approval from the Institutional Research Ethics Committee were obtained.

\section{Cell line culture, transfection and reagents}

OVCAR3 is a human ovarian cancer cell line purchased from American Type Culture Collection (ATCC, Rockville, MD, USA), and were maintained in Dulbecco's modified Eagle's medium (DMEM, Invitrogen, St. Louis, MO, USA) supplemented with L-glutamine and 20\% fetal bovine serum (FBS; Sigma-Aldrich, St Louis, MO, USA) in a humidified chamber with $5 \% \mathrm{CO} 2$ at $37^{\circ} \mathrm{C}$. The plasmids that express PLGF, or ZEB2, or short hairpin interfering RNA for PLGF (shPLGF), or shZEB2, or control scrambled sequence (scr), were all purchased from Origene (Beijing, China). Transfection was performed with $2 \mu \mathrm{g}$ plasmids using the Lipofectamine 2000, according to the manufacturer's instructions (Invitrogen). Cells were analyzed 48 hours after transfection. Inhibitors PD98059 (used at a dose of $10 \mu \mathrm{g} / \mathrm{ml}$ ), SB203580 (used at a dose of $1 \mu \mathrm{g} /$ $\mathrm{ml}$ ), LY294002 (used at a dose of $20 \mu \mathrm{g} / \mathrm{ml}$ ), and SP600125 (used at a dose of $10 \mu \mathrm{g} / \mathrm{ml}$ ) were all purchased from Sigma-Aldrich (St. Louis, MO, USA).

Transwell cell invasion assay

Cells of $5 \times 10^{5}$ were plated into the top side of polycarbonate transwell filter coated with Matrigel in the upper chamber of the BioCoatTM Invasion Chambers (BD, Bedford, MA, USA) and incubated at $37^{\circ} \mathrm{C}$ for 


\section{Cellular Physiology Cell Physiol Biochem 2016;38:351-358 \begin{tabular}{l|l|l} 
and Biochemistry & Dublished online: January 29, 2016 & $\begin{array}{l}\text { (c) } 2016 \text { The Author(s). Published by S. Karger AG, Basel } \\
\text { www.karger.com/cpb }\end{array}$
\end{tabular} \\ Song et al.: PLGF Promotes OVC Cell Invasion via ZEB2}

22 hours. The cells inside the upper chamber with cotton swabs were then removed. Migratory and invasive cells on the lower membrane surface were fixed, stained with hematoxylin, and counted for 10 random 100x fields per well. Cell counts are expressed as the mean number of cells per field of view. Five independent experiments were performed and the data are presented as mean \pm standard deviation (SD).

\section{Scratch wound healing assay}

Scratch wound healing assay was performed as has been described previously [21]. Cells were seeded in 24-well plates at a density of $10^{4}$ cells/well in complete DMEM and cultured to confluence. The cell monolayer was serum starved overnight in DMEM prior to initiating of the experiment. Confluent cell monolayer were then scraped with a yellow pipette tip to generate scratch wounds and washed twice with media to remove cell debris. Cells were incubated at $37^{\circ} \mathrm{C}$ for 24 hours with the conditioned media containing either TGFß1, or BMP7, or both, or null control. Time lapse images were captured after 12 hours. Images were captured from five randomly selected fields in each sample, and the wound areas are calculated by NIH ImageJ software (Bethesda, MA, USA).

\section{Quantitative PCR (RT-qPCR)}

Total RNA was extracted from the cultured cells using RNeasy kit (Qiagen, Hilden, Germany). For cDNA synthesis, complementary DNA (cDNA) was randomly primed from $2 \mu \mathrm{g}$ of total RNA using the Omniscript reverse transcription kit (Qiagen). RT-qPCR was subsequently performed in triplicate with a 1:4 dilution of cDNA using the Quantitect SyBr green PCR system (Qiagen). All primers were purchased from Qiagen. Data were collected and analyzed using $2^{-\Delta \Delta \mathrm{Ct}}$ method. Values of genes were first normalized against $\alpha$-tubulin, and then compared to the experimental controls.

\section{Western blot}

For analysis of total protein, the protein was extracted from the ovary specimens or from the cultured cells, and homogenized in RIPA lysis buffer ( $1 \%$ NP40, $0.1 \%$ SDS, $100 \mu \mathrm{g} / \mathrm{ml}$ phenylmethylsulfonyl fluoride, $0.5 \%$ sodium deoxycholate, in PBS) on ice. The supernatants were collected after centrifugation at $12,000 \times \mathrm{g}$ at $4^{\circ} \mathrm{C}$ for $20 \mathrm{~min}$. Protein concentration was determined using a BCA protein assay kit (Bio-rad, China), and whole lysates were mixed with $4 \times$ SDS loading buffer $(125 \mathrm{mmol} / \mathrm{l} \mathrm{Tris-HCl,} 4 \% \mathrm{SDS}, 20 \%$ glycerol, $100 \mathrm{mmol} / \mathrm{l} \mathrm{DTT}$, and $0.2 \%$ bromophenol blue) at a ratio of $1: 3$. Protein samples were heated at $100^{\circ} \mathrm{C}$ for $5 \mathrm{~min}$ and were separated on SDS-polyacrylamide gels. The separated proteins were then transferred to a PVDF membrane. The membrane blots were first probed with a primary antibody. After incubation with horseradish peroxidase-conjugated second antibody, autoradiograms were prepared using the enhanced chemiluminescent system to visualize the protein antigen. The signals were recorded using X-ray film. Primary antibodies for Western Blot are anti-PLGF (Invitrogen), anti-ZEB2 and $\alpha$-tubulin (all from Cell Signaling, San Jose, CA, USA). $\alpha$-tubulin was used as protein loading controls. Secondary antibody is HRP-conjugated anti-rabbit (Jackson ImmunoResearch Labs, West Grove, PA, USA). Images shown in the figures were representative from 5 individuals. Densitometry of Western blots was quantified with NIH ImageJ software. The protein levels were first normalized to $\alpha$-tubulin, and then normalized to experimental controls.

\section{Statistics}

All statistical analyses were carried out using the SPSS 18.0 statistical software package. All values in cell and animal studies are depicted as mean \pm standard deviation and are considered significant if $p<$ 0.05. All data were statistically analyzed using one-way ANOVA with a Bonferroni correction, followed by Fisher' Exact Test for comparison of two groups. Bivariate correlations were calculated by Spearman's rank correlation coefficients.

\section{Results}

PLGF and ZEB2 levels upregulate and correlate in OVC specimens

First, we found that the PLGF levels significantly increased in the OVC specimens, compared to paired non-tumor ovary tissue (NT, Fig. 1A). We then examined the levels of 


\section{Cellular Physiology Cell Physiol Biochem 2016;38:351-358 \begin{tabular}{ll|l} 
DOI: 10.1159/000438635 & $\begin{array}{l}\text { O 2016 The Author(s). Published by S. Karger AG, Basel } \\
\text { www.karger.com/cpb }\end{array}$
\end{tabular} \\ Song et al.: PLGF Promotes OVC Cell Invasion via ZEB2}

Fig. 1. PLGF and ZEB2 levels upregulate and correlate in OVC specimens. (A) PLGF levels significantly increased in the OVC specimens, compared to paired non-tumor ovary tissue (NT), by Western blot. (B) ZEB2 levels significantly increased in OVC specimens, compared to NT, by Western blot. (C) A strong positive correlation was detected between PLGF and ZEB2 levels in OVC specimens $(r=0.79$, $\mathrm{p}<0.0001, \mathrm{~N}=25$ ). $* \mathrm{p}<0.05$.

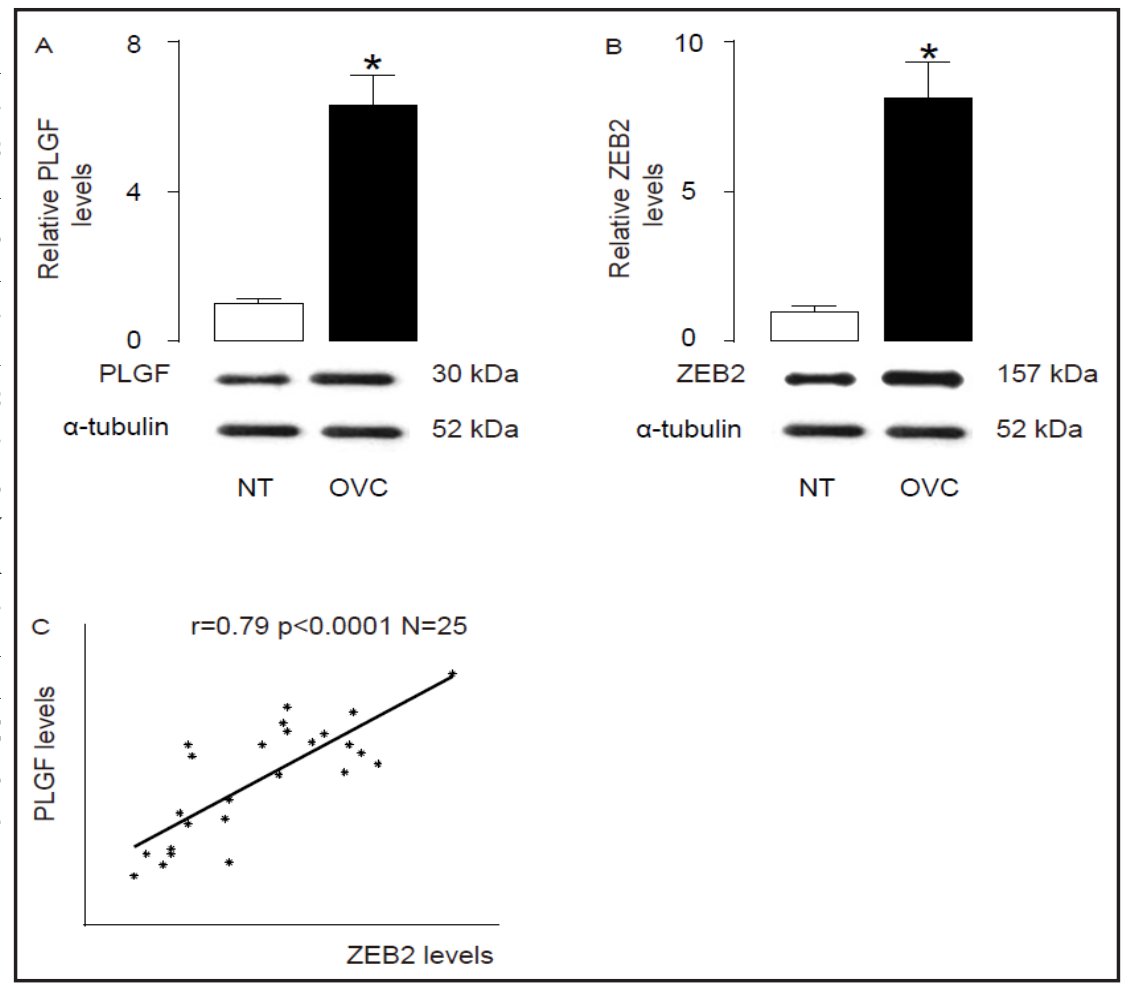

ZEB2 in OVC specimens and found that the levels of ZEB2 significantly increased in OVC (Fig. 1B). Moreover, the levels of PLGF and ZEB2 strongly correlated in the OVC specimens (Fig. $1 C, R=0.79, p<0.0001, N=25$ ), suggesting presence of a possible regulatory relationship between PLGF and ZEB2 in OVC cells.

ZEB2 does not regulate PLGF levels in OVC cells

Then we used a human OVC cell line, OVCAR3, to examine whether ZEB2 may regulate PLGF levels. We transfected the OVCAR3 cells with either a ZEB2 overexpressing plasmid (ZEB2), or a small short hairpin interfering RNA for ZEB2 (shZEB2). The OVCAR3 cells were transfected with a scrambled sequence as a control (scr). First, we confirmed the modulation of ZEB2 levels in these cells by mRNA (Fig. 2A), and by Western blot for cellular protein (Fig. 2B). We found that modification of ZEB2 in OVCAR3 cells did not alter PLGF levels, by mRNA (Fig. 2C), by Western blot for cellular protein (Fig. 2D), and by ELISA on the secreted protein in the conditioned media (Fig. 2E). These data suggest that ZEB2 does not regulate PLGF levels in OVC cells.

\section{PLGF increases ZEB2 levels in OVC cells}

Next, we examined whether PLGF may regulate ZEB2 in OVC cells. We transfected the OVCAR3 cells with either a PLGF overexpressing plasmid (PLGF), or a small short hairpin interfering RNA for PLGF (shPLGF). The OVCAR3 cells were transfected with a scrambled sequence as a control (scr). First, we confirmed the modulation of PLGF levels in these cells by mRNA (Fig. 3A), and by Western blot for cellular protein (Fig. 3B). We found that overexpression of PLGF in OVCAR3 cells increased ZEB2 levels, while inhibition of PLGF in OVCAR3 cells decreased ZEB2 levels, by mRNA (Fig. 3C), by Western blot for cellular protein (Fig. 3D). These data suggest that PLGF activates ZEB2 in OVC cells.

PLGF enhances cell invasion in OVC cells

We then examined whether the effects of PLGF on ZEB2 may result in changes in cell invasion. We found that PLGF overexpression significantly increased the invasiveness 
Fig. 2. ZEB2 does not regulate PLGF in OVC cells. We transfected the OVCAR3 cells with either a ZEB2 overexpressing plasmid (ZEB2), or a small short hairpin interfering RNA for ZEB2 (shZEB2). The OVCAR3 cells were transfected with a scrambled sequence as a control (scr). (A-B) The ZEB2 levels by mRNA (A) and by Western blot (B). (C-E) The PLGF levels by mRNA (C), by Western blot (D) and by ELISA on the secreted protein (E). $* \mathrm{p}<0.05$. NS: non-significant, $\mathrm{N}=5$.

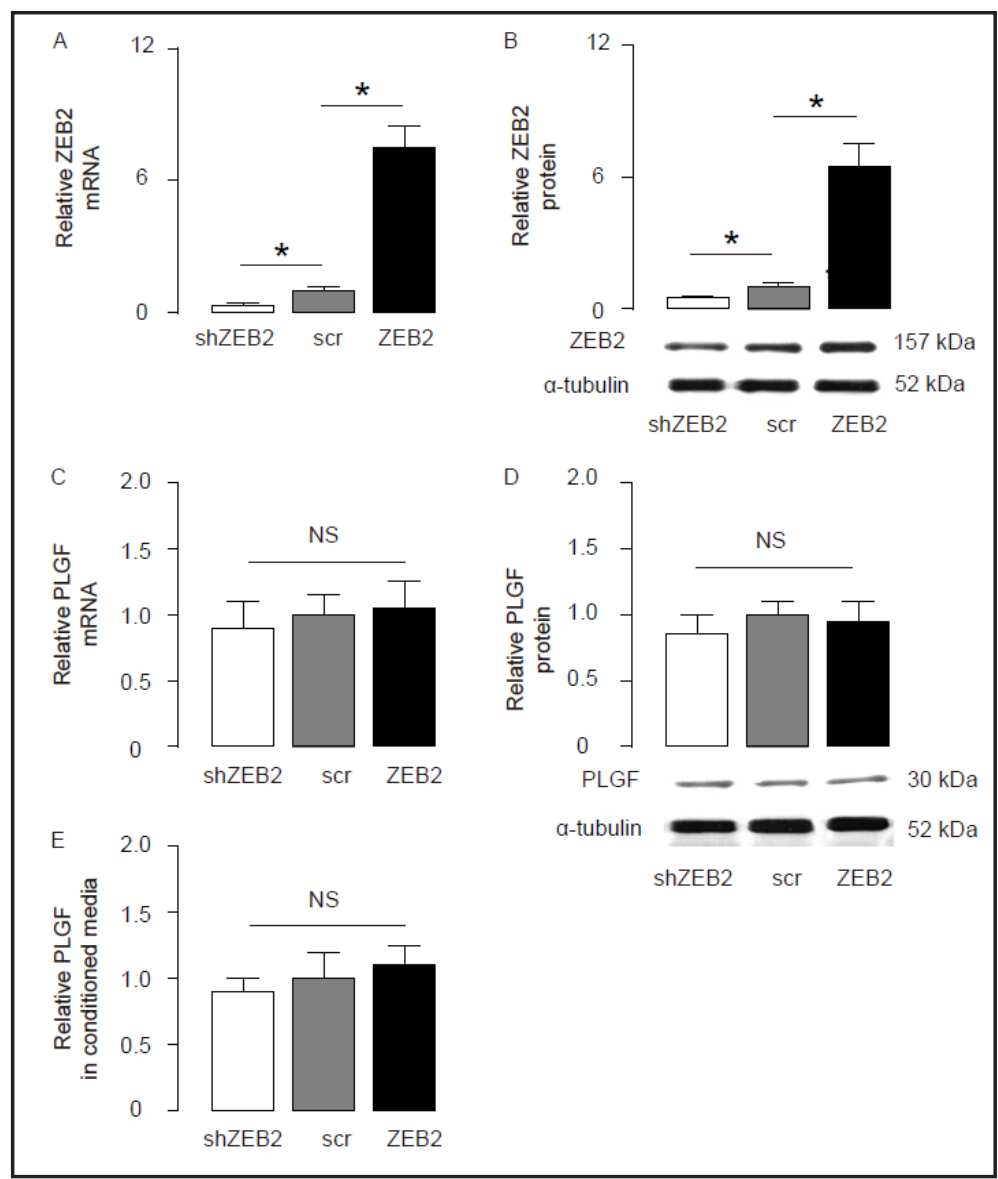

Fig. 3. PLGF increases ZEB2 levels in OVC cells. We transfected the OVCAR3 cells with either a PLGF overexpressing plasmid (PLGF), or a small short hairpin interfering RNA for PLGF (shPLGF). The OVCAR3 cells were transfected with a scrambled sequence as a control (scr). (A-B) The PLGF levels by mRNA (A) and by Western blot (B). (C-D) The ZEB2 levels by mRNA (C) and by Western blot (D). * p $<0.05$, $\mathrm{N}=5$.

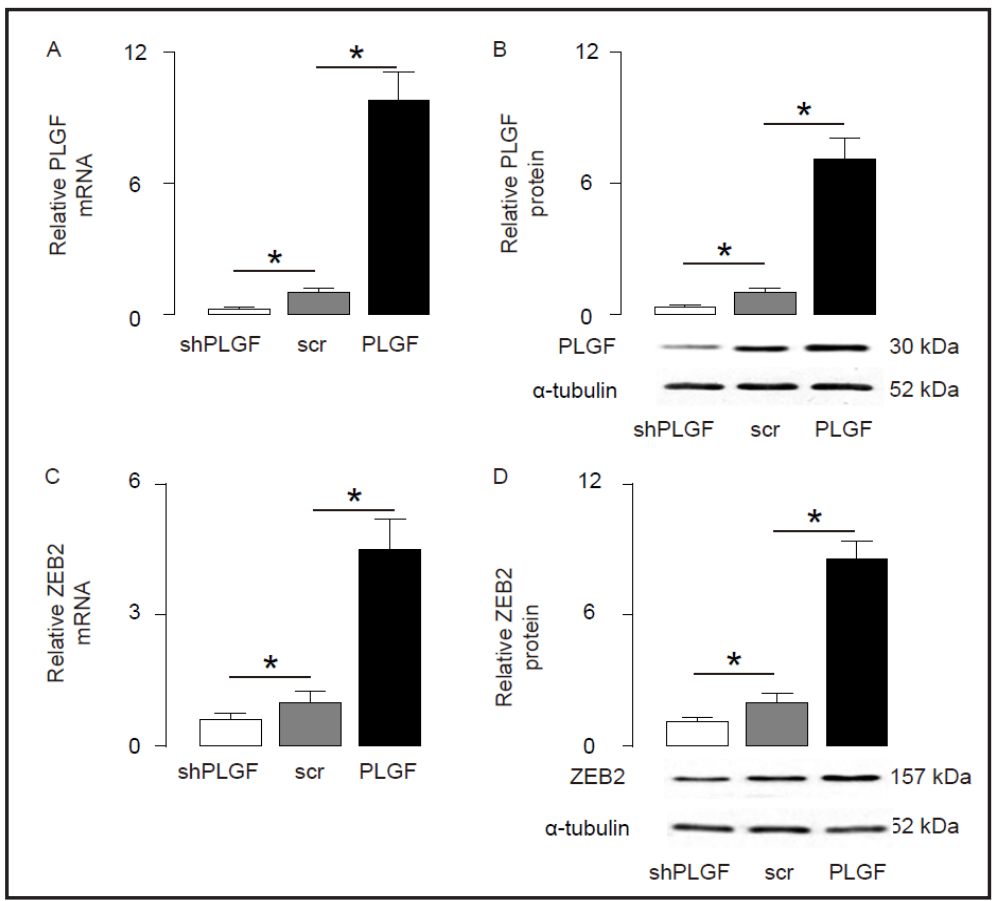

of OVCAR3 cells, while inhibition of PLGF in OVCAR3 cells significantly decreased the invasiveness of OVCAR3 cells in a transwell cell invasion assay, shown by representative 


\section{Cellular Physiology Cell Physiol Biochem 2016;38:351-358

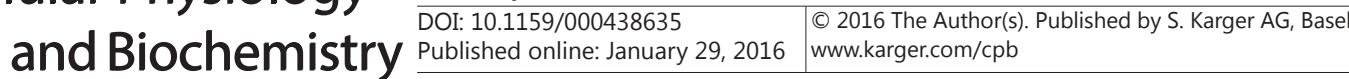 \\ Song et al.: PLGF Promotes OVC Cell Invasion via ZEB2}

Fig. 4. PLGF enhances cell invasion in OVC cells. (A-B) Cell invasiveness of PLGF-modified cells was examined in a transwell cell invasion assay, shown by representative images (A), and by quantification (B). (C) Cell invasiveness of PLGF-modified cells was examined in a scratch wound healing assay. $* \mathrm{p}<0.05, \mathrm{~N}=5$.

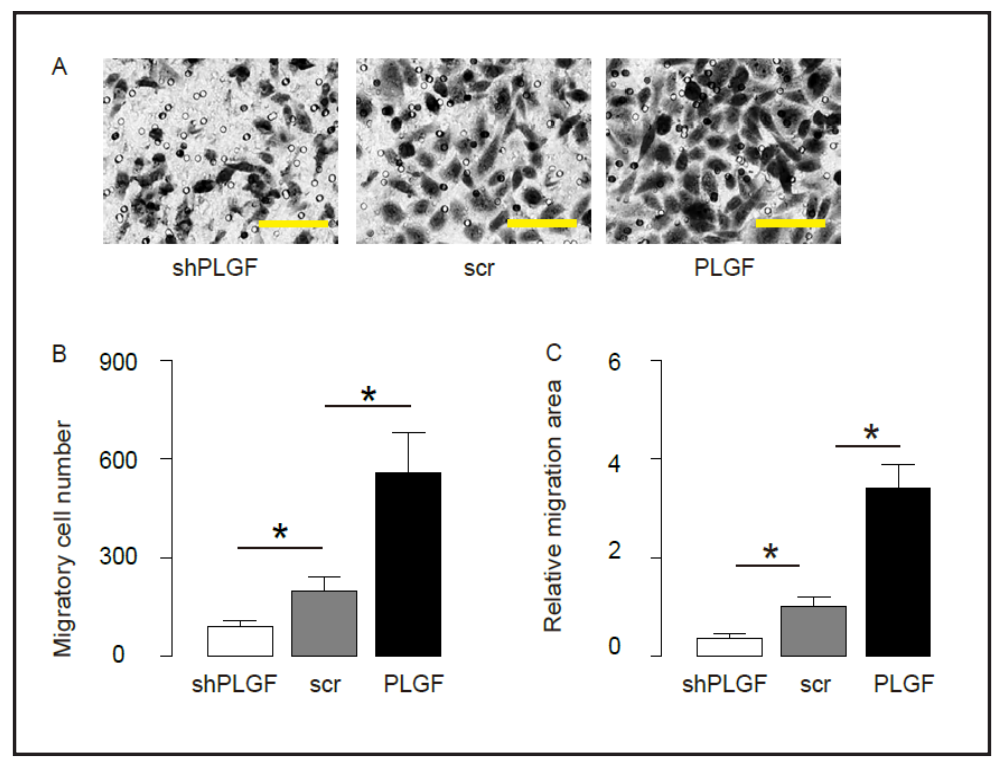

Fig. 5. PLGF activates ZEB2 via MAPK-p38 signaling pathway. We analyzed the signaling pathway through which PLGF activates ZEB2. (A-C) Application of a specific MAPK-p38 signaling pathway inhibitor, SB203580 (1 $\mu \mathrm{g} / \mathrm{ml})$, but not application of either a specific MAPK-p42/p44 signaling pathway inhibitor, PD98059 (10 $\mu \mathrm{g} / \mathrm{ml})$, or a specific PI3k/ Akt signaling pathway inhibitor, LY294002 (20 $\mu \mathrm{g} / \mathrm{ml})$, or a specific JNK pathway inhibitor, SP600125 (10 $\mu \mathrm{g} / \mathrm{ml})$, to PLGF-overexpressing OVCAR3 cells substantially abolished the effect of PLGF on ZEB2 activation, by mRNA (A), by Western blot quantification (B), and by Western blot representative images (C). ${ }^{*} \mathrm{p}<0.05, \mathrm{~N}=5$. NS: non-significant.

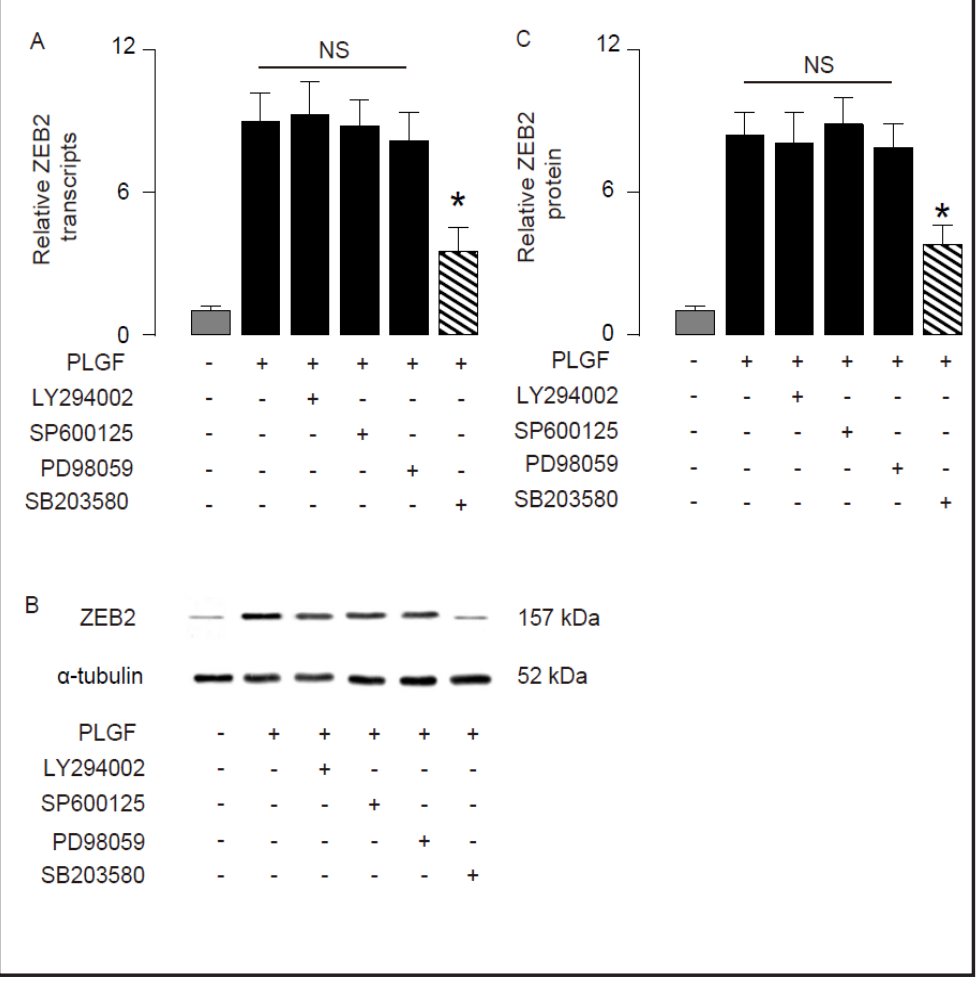

images (Fig. 4A), and by quantification (Fig. 4B). Similar results were obtained in a scratch wound healing assay (Fig. 4C). Thus, PLGF enhances cell invasion in OVC cells.

PLGF activates ZEB2 via MAPK-p38 signaling pathway

Finally, we analyzed the signaling pathway through which PLGF activates ZEB2. Application of a specific MAPK-p38 signaling pathway inhibitor, SB203580 (1 $\mu \mathrm{g} / \mathrm{ml})$, but not application of either a specific MAPK-p42/p44 signaling pathway inhibitor, PD98059 $(10 \mu \mathrm{g} / \mathrm{ml})$, or a specific PI3k/Akt signaling pathway inhibitor, LY294002 $(20 \mu \mathrm{g} / \mathrm{ml})$, or a specific JNK pathway inhibitor, SP600125 $(10 \mu \mathrm{g} / \mathrm{ml})$, to PLGF-overexpressing OVCAR3 cells 


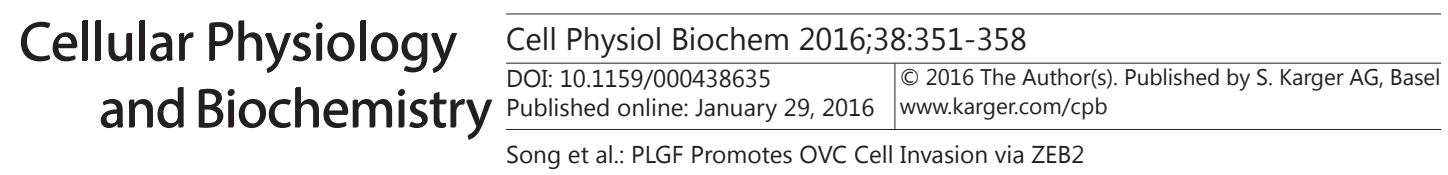

substantially abolished the effect of PLGF on ZEB2 activation, by mRNA (Fig. 5A), by Western blot for cellular protein (Fig. 5B-C). These data suggest that PLGF may activate ZEB2 via MAPK-p38 signaling pathway.

\section{Discussion}

Understanding the molecular mechanisms underlying the cancer metastases may substantially improve the diagnosis and therapy of OVC. All the events that relate to cancer cell outgrowth, invasion and migration are critical for cancer metastases [22]. PLGF, MMPs and ZEB2 are key factors involved in cancer cell invasion and cancer-associated vascularization. Most recently, their relationship has been reported [23, 24]. Nevertheless, the crosstalk among these factors in OVC is not known, until recently, we reported that PLGF promoted metastases of OVC cells through miR-543-regulated MMP7.

Here we found strong correlation of PLGF and ZEB2 levels in the OVC specimens, and both were significantly upregulated. These data suggest a possible relationship between PLGF and ZEB2 in OVC cells. To prove this hypothesis, we used several human OVC cell lines, e.g. OVCAR3, H460, to examine the interaction of PLGF and ZEB2. Since we got similar results, only data from OVCAR3 cells were shown here. We found that overexpression of PLGF in OVCAR3 cells increased expression of ZEB2, while inhibition of PLGF in OVCAR3 cells decreased expression of ZEB2. However, ZEB2 modification did not alter PLGF levels in OVC cells. These data suggest that PLGF may function upstream of ZEB2 and acts as a regulator of ZEB2 in OVC cells.

We then analyzed how PLGF may affect the expression of ZEB2. Application of a specific MAPK-p38 inhibitor to PLGF-overexpressing OVCAR3 cells substantially abolished the effect of PLGF on ZEB2 activation. Of note, the application of this inhibitor did not alter the PLGF levels in the PLGF-overexpressing OVCAR3 cells. Thus, PLGF may increase expression of ZEB2 via MAPK-p38 signaling pathway.

Anti-PLGF was recently applied in the clinical trials targeting cancer-related angiogenesis, but the mechanism has been regarded as inhibition of endothelial growth and capillary permeability in the cancer tissue. Now our data suggest that anti-PLGF may also decrease MMP7 and ZEB2 expression to impair the extracellular matrix degradation and cancer cell EMT in OVC cells, which may enhance cancer cell metastases from two aspects.

Our study thus illustrates a novel model for the control of the invasiveness of OVC cells. Further delineation of the precise molecular mechanisms underlying the regulation of ZEB2 by PLGF as well as the regulation of MMP7 by PLGF and the possible interaction between two mechanisms may substantially improve our understanding of the OVC cell metastasis and may provide novel therapeutic strategies for OVC treatment.

\section{Disclosure Statement}

The authors have declared that no competing interests exist.

\section{References}

1 Zhang S, Hou X, Zi S, Wang Y, Chen L, Kong B: Polymorphisms of receptor for advanced glycation end products and risk of epithelial ovarian cancer in chinese patients. Cell Physiol Biochem 2013;31:525-531.

2 Sun N, Zhang Q, Xu C, Zhao Q, Ma Y, Lu X, Wang L, Li W: Molecular regulation of ovarian cancer cell invasion. Tumour Biol 2014;35:11359-11366.

3 Chen Q, Qin R, Fang Y, Li H: Berberine sensitizes human ovarian cancer cells to cisplatin through mir-93/ pten/akt signaling pathway. Cell Physiol Biochem 2015;36:956-965. 


\section{Cellular Physiology Cell Physiol Biochem 2016;38:351-358 \begin{tabular}{cl|l} 
DOI: 10.1159/000438635 & O 2016 The Author(s). Published by S. Karger AG, Basel \\
and Bu.karger.com/cpb
\end{tabular} \\ Song et al.: PLGF Promotes OVC Cell Invasion via ZEB2}

4 Ge T, Yin M, Yang M, Liu T, Lou G: Microrna-302b suppresses human epithelial ovarian cancer cell growth by targeting runx1. Cell Physiol Biochem 2014;34:2209-2220.

5 He QZ, Luo XZ, Wang K, Zhou Q Ao H, Yang Y, Li SX, Li Y, Zhu HT, Duan T: Isolation and characterization of cancer stem cells from high-grade serous ovarian carcinomas. Cell Physiol Biochem 2014;33:173-184.

6 Jeong GO, Shin SH, Seo EJ, Kwon YW, Heo SC, Kim KH, Yoon MS, Suh DS, Kim JH: Taz mediates lysophosphatidic acid-induced migration and proliferation of epithelial ovarian cancer cells. Cell Physiol Biochem 2013;32:253-263.

7 Teng Y, Zhao L, Zhang Y, Chen W, Li X: Id-1, a protein repressed by mir-29b, facilitates the tgfbeta1-induced epithelial-mesenchymal transition in human ovarian cancer cells. Cell Physiol Biochem 2014;33:717-730.

8 Dufour A, Overall CM: Missing the target: Matrix metalloproteinase antitargets in inflammation and cancer. Trends Pharmacol Sci 2013;34:233-242.

9 Ferrara N: Vascular endothelial growth factor. Arterioscler Thromb Vasc Biol 2009;29:789-791.

10 Xiao X, Prasadan K, Guo P, El-Gohary Y, Fischbach S, Wiersch J, Gaffar I, Shiota C, Gittes GK: Pancreatic duct cells as a source of vegf in mice. Diabetologia 2014;57:991-1000.

11 Xiao X, Guo P, Chen Z, El-Gohary Y, Wiersch J, Gaffar I, Prasadan K, Shiota C, Gittes GK: Hypoglycemia reduces vascular endothelial growth factor a production by pancreatic beta cells as a regulator of beta cell mass. J Biol Chem 2013;288:8636-8646.

12 Carmeliet P, Moons L, Luttun A, Vincenti V, Compernolle V, De Mol M, Wu Y, Bono F, Devy L, Beck H, Scholz D, Acker T, DiPalma T, Dewerchin M, Noel A, Stalmans I, Barra A, Blacher S, Vandendriessche T, Ponten A, Eriksson U, Plate KH, Foidart JM, Schaper W, Charnock-Jones DS, Hicklin DJ, Herbert JM, Collen D, Persico MG: Synergism between vascular endothelial growth factor and placental growth factor contributes to angiogenesis and plasma extravasation in pathological conditions. Nat Med 2001;7:575-583.

13 Eriksson A, Cao R, Pawliuk R, Berg SM, Tsang M, Zhou D, Fleet C, Tritsaris K, Dissing S, Leboulch P, Cao Y: Placenta growth factor-1 antagonizes vegf-induced angiogenesis and tumor growth by the formation of functionally inactive plgf-1/vegf heterodimers. Cancer Cell 2002;1:99-108.

14 Hu Q, Tong S, Zhao X, Ding W, Gou Y, Xu K, Sun C, Xia G: Periostin mediates tgf-beta-induced epithelial mesenchymal transition in prostate cancer cells. Cell Physiol Biochem 2015;36:799-809.

15 Sa Y, Li C, Li H, Guo H: Timp-1 induces alpha-smooth muscle actin in fibroblasts to promote urethral scar formation. Cell Physiol Biochem 2015;35:2233-2243.

16 Lan A, Qi Y, Du J: Akt2 mediates tgf-beta1-induced epithelial to mesenchymal transition by deactivating gsk3beta/snail signaling pathway in renal tubular epithelial cells. Cell Physiol Biochem 2014;34:368-382.

17 Davidson B, Reich R, Risberg B, Nesland JM: The biological role and regulation of matrix metalloproteinases (mmp) in cancer. Arkh Patol 2002;64:47-53.

18 Rhee JS, Coussens LM: Recking mmp function: Implications for cancer development. Trends Cell Biol 2002;12:209-211.

19 Guo Y, Lang X, Lu Z, Wang J, Li T, Liao Y, Jia C, Zhao W, Fang H: Mir-10b directly targets zeb1 and pik3ca to curb adenomyotic epithelial cell invasiveness via upregulation of e-cadherin and inhibition of akt phosphorylation. Cell Physiol Biochem 2015;35:2169-2180.

20 Schmalhofer 0, Brabletz S, Brabletz T: E-cadherin, beta-catenin, and zeb1 in malignant progression of cancer. Cancer Metastasis Rev 2009;28:151-166.

21 Liang CC, Park AY, Guan JL: In vitro scratch assay: A convenient and inexpensive method for analysis of cell migration in vitro. Nat Protoc 2007;2:329-333.

22 Joyce JA, Pollard JW: Microenvironmental regulation of metastasis. Nat Rev Cancer 2009;9:239-252.

23 Chen Y, Jiang T, Mao A, Xu J: Esophageal cancer stem cells express plgf to increase cancer invasion through mmp9 activation. Tumour Biol 2014;35:12749-12755.

24 Zhou X, Qi Y: Plgf inhibition impairs metastasis of larynx carcinoma through mmp3 downregulation. Tumour Biol 2014;35:9381-9386. 